\title{
Environmental exposure to cadmium and risk of cancer: a prospective population-based study
}

Tim Nawrot, Michelle Plusquin, Janneke Hogervorst, Harry A Roels, Hilde Celis, Lutgarde Thijs, Jaco Vangronsveld, Etienne Van Hecke, Jan A Staessen

\section{Summary}

Background Cadmium is a ubiquitous environmental pollutant, which accumulates in the human body such that 24-h urinary excretion is a biomarker of lifetime exposure. We aimed to assess the association between environmental exposure to cadmium and cancer.

Methods We recruited a random population sample $(n=994)$ from an area close to three zinc smelters and a reference population from an area with low exposure to cadmium. At baseline (1985-89), we measured cadmium in urine samples obtained over $24 \mathrm{~h}$ and in the soil of participants' gardens, and followed the incidence of cancer until June 30, 2004. We used Cox regression to calculate hazard ratios for cancer in relation to internal (ie, urinary) and external (ie, soil) exposure to cadmium, while adjusting for covariables.

Findings Cadmium concentration in soil ranged from $0.8 \mathrm{mg} / \mathrm{kg}$ to $17.0 \mathrm{mg} / \mathrm{kg}$. At baseline, geometric mean urinary cadmium excretion was $12.3 \mathrm{nmol} /$ day for people in the high-exposure area, compared with $7 \cdot 7 \mathrm{nmol} / \mathrm{day}$ for those in the reference (ie, low-exposure) area $(\mathbf{p}<0.0001)$. During follow-up (median 17.2 years [range $0 \cdot 6-18 \cdot 8]), 50$ fatal cancers and 20 non-fatal cancers occurred, of which 18 and one, respectively, were lung cancers Overall cancer risk was significantly associated with a doubling of 24-h cadmium excretion (hazard ratio 1.31 [95\% CI 1.03-1.65], p=0 026. Population-attributable risk of lung cancer was 67\% (95\% CI 33-101) in the high-exposure area, compared with that of $73 \%(38-108)$ for smoking. For lung cancer, adjusted hazard ratio was $1 \cdot 70(1 \cdot 13-2 \cdot 57$, $\mathrm{p}=\mathbf{0} \cdot 011$ ) for a doubling of $24-\mathrm{h}$ urinary cadmium excretion, $4 \cdot 17(1 \cdot 21-14 \cdot 4, \mathrm{p}=0 \cdot 024)$ for residence in the highexposure area versus the low-exposure area, and $1.57(1 \cdot 11-2 \cdot 24, \mathrm{p}=0 \cdot 012)$ for a doubling of cadmium concentration in soil.

Interpretation Historical pollution from non-ferrous smelters continues to present a serious health hazard necessitating targeted preventive measures.

\section{Introduction}

Cadmium is a metal with high toxic effects, has an elimination half-life of 10-30 years, and accumulates in the human body, particularly the kidney. Urinary excretion of cadmium over $24 \mathrm{~h}$ is a biomarker of lifetime exposure. ${ }^{1,2}$ Exposure to cadmium occurs through intake of contaminated food or water, or by inhalation of tobacco smoke or polluted air., ${ }^{1,2}$ We have shown that environmental exposure to cadmium in north-east Belgium in the neighbourhood of zinc smelters was associated with about 30\% increased urinary cadmium excretion, ${ }^{3}$ renal dysfunction, ${ }^{4,5}$ increased calciuria, ${ }^{6}$ osteoporosis, ${ }^{7}$ and a $35 \%$ population-attributable risk of fractures. ${ }^{7}$

In 1993, the International Agency for Research on Cancer (IARC) classified cadmium as a human carcinogen. $^{8}$ As reviewed by Verougstraete and colleagues, ${ }^{9} \quad$ longitudinal studies have shown consistently that workers exposed to cadmium or cadmium compounds are at increased risk of lung cancer. In five large cohorts of industrial workers, ${ }^{10-14}$ standardised mortality ratios ranged from 101 to 176 (median 120). ${ }^{9}$ However, in a study ${ }^{15}$ of 926 men who manufactured nickel-cadmium batteries in the UK followed up from 1947 to 2000, the ratio was non- significantly increased to 111 . Few population-based studies, mostly Japanese, ${ }^{16-18}$ have addressed the association between cancer and environmental exposure to cadmium, and have reported inconsistent results. We started recruitment of Flemish participants of the Cadmium in Belgium Study (CadmiBel) ${ }^{19}$ on Sept 1, 1985. . $^{3-7}$ We aimed to assess prospectively the incidence of fatal cancer and non-fatal cancer until June 30, 2004, to investigate whether environmental exposure to cadmium is associated with increased risk of cancer, particularly that of the lung.

\section{Methods}

\section{Study population}

The Flemish CadmiBel participants were recruited from Sept 1, 1985, to Dec 17, 1989, ${ }^{19}$ and were from north-east Belgium (Noorderkempen); this region has an area contaminated with cadmium and a reference area with low exposure to cadmium. We selected ten districts where we expected mean concentration of cadmium in soil to be more than $3 \mathrm{mg} / \mathrm{kg}$ or less than $1 \mathrm{mg} / \mathrm{kg}$ on the basis of a preliminary screen done 1983-84 by the Research Institute for Ecology and Forestry, Genk, Belgium. The environmentally contaminated (ie, high-exposure) study area of $300 \mathrm{~km}^{2}$
Published Online January 16, 2006 DOI:10.1016/S1470-2045(06) 70545-9

Study Coordinating Centre, Hypertension and Cardiovascular Rehabilitation Unit, Department of Cardiovascular Diseases (T Nawrot PhD, M Plusquin MSc H Celis MD, L Thijs MSc, J A Staessen MD), and Social and Economic Geography Section, Department of Geography and Geology

(Prof E Van Hecke, PhD), University of Leuven, Leuven, Belgium; Section of Environmental Biology, Department of Chemistry, Biology and Geology, University of Hasselt, Diepenbeek, Belgium (Prof J Vangronsveld PhD, J Hogervorst MSc); and Toxicology and Occupational Medicine Unit, Catholic University of Louvain, Brussels, Belgium (Prof H A Roels PhD)

Correspondence to: Dr Jan A Staessen, Study Coordinating Centre, Laboratory of Hypertension, Department of Cardiovascular Diseases, University of Leuven, Campus Gasthuisberg, Herestraat 49 bus 702, B-3000 Leuven, Belgium jan.staessen@ med.kuleuven.be 


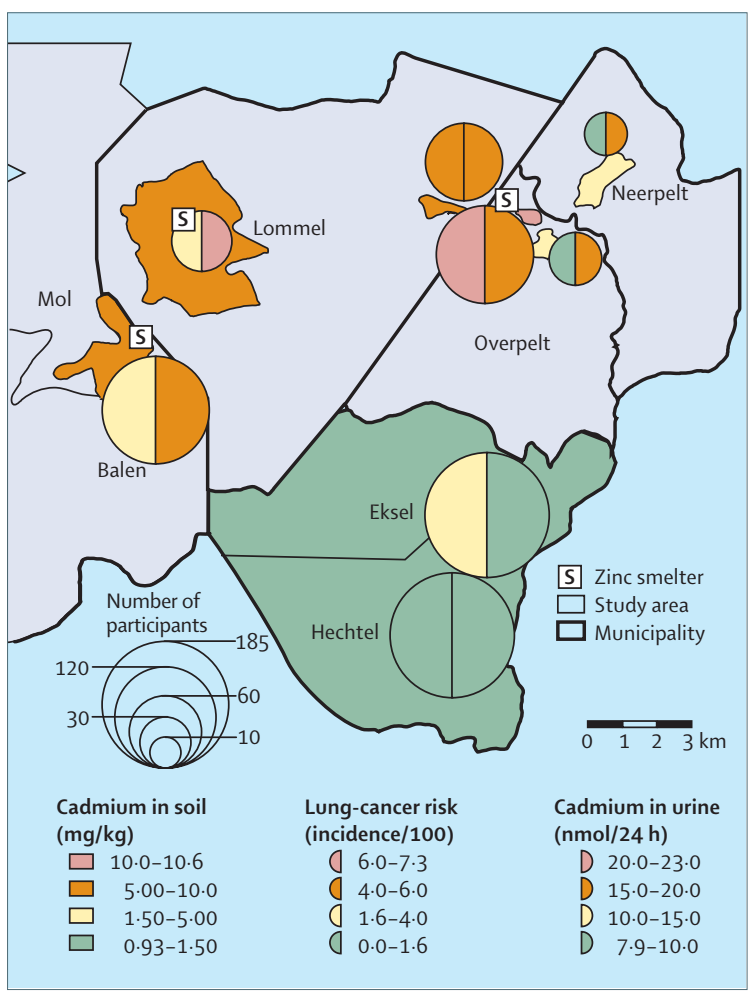

Figure 1: Geographical association between risk of lung cancer, 24-h urinary cadmium excretion, and cadmium concentration in soil of participants' gardens

has an estimated population of 9840 , borders on three zinc smelters, and consists of six districts of the municipalities Balen, Lommel, and Overpelt (figure 1). This area remains polluted by toxic metals, despite dismantlement of the smelter in Lommel in 1974, transition from pyrolytic to electrolytic zinc refining in Overpelt in 1974, and a complete stop to cadmium production in Overpelt in 1992 and Balen in 2002. The reference (ie, low exposure) study area has 9390 inhabitants, is located more than $10 \mathrm{~km}$ south-east of the smelters, and includes four districts of the villages Hechtel and Eksel (figure 1). In the 1980s, equal proportions of residents in these two areas worked in the agricultural sector or in the service industry. However, men in the high-exposure area were more likely to be employed at zinc smelters, whereas those living in the low-exposure area worked more frequently at coal mines about $15 \mathrm{~km}$ south of Hechtel.

In every district, we identified a random population sample stratified by sex and age (20-39 years vs $40-59$ years $v s \geqslant 60$ years), with the aim of recruiting equal numbers in each group. The six municipalities gave listings of all inhabitants sorted by address. Households, defined as those who lived at the same address, were the sampling unit. We numbered households consecutively, and generated a randomnumber list by use of SAS random function.
Households with a number matching the list were invited; household members older than 20 years were eligible, but were not included if the quota of age-sex stratum had been met. To ascertain data for occupational exposure to cadmium, lists of participants who reported working, or having worked, at the zincrefining plants were given to the occupational-health physician of the company that owned the plants. The physician gave details of these participants' employment history and their role in the production process.

Of 1107 participants, ${ }^{5,7}$ we excluded 113 people from analyses because of: previous history of cancer $(n=10$, four in low-exposure area vs six in high-exposure area); pneumoconiosis, which is associated with a substantially increased risk of lung cancer ${ }^{20}(\mathrm{n}=22,17$ in low-exposure area vs five in high-exposure area); or no 24-h urine sample $(\mathrm{n}=81,49$ in low-exposure area vs 32 in highexposure area). Thus, the study population consisted of 994 people: 521 residents from the high-exposure (ie, smelter) area and 473 from the low-exposure area. The ethics committee of the University of Leuven, Belgium, approved the study and follow-up of the participants. Participants signed the questionnaire to confirm informed consent.

At baseline, we used a validated questionnaire that inquired about lifestyle, past and current residence, possible exposure to cadmium at work, smoking habits, and previous medical history. At baseline, every household was visited by the same study nurse, who gave participants a self-administered questionnaire and container for urine sampling. If needed, nurses assisted participants in completion of the questionnaire, and instructed participants on how to obtain urine samples without external contamination. 1 week later, nurses revisited the homes to collect the questionnaire and urine samples and to obtain a sample of venous blood. ${ }^{19}$ This procedure was also used during follow-up., The prinicipal investigator (JAS) coordinated the administration of questionnaires and wrote the manuals of operation, code books, and SAS programs for compliation of the coded data sheets; we developed these programs to convert questionnaire replies after coding them into analysable variables. Questionnaires were coded by trained nurses, and technicians entered the data into an SAS database. For quality assurance, $10 \%$ of questionnaires coded by a nurse were selected randomly and recoded by another nurse. All data were inputted twice into the database by different technicians. Duplicate datasets were compared with the PROC COMPARE application in the SAS software to trace input errors. ${ }^{19}$ Data coders and SAS programmes checked for internal consistency of questionnaire replies.

Because smoking is a major cause of exposure to cadmium in the general population and because cadmium is a cumulative toxicant, participants were classified as smokers if they had ever used smoking materials. Socioeconomic status was coded according to 
the methods of the UK office of population censuses and surveys, ${ }^{21}$ and condensed into a scale with scores ranging from 1 to $3.5,7$

\section{Analyses of exposure}

Participants collected urine samples obtained over $24 \mathrm{~h}$ in a wide-neck polyethylene container. Cadmium concentration in the blood and urine were measured with an electrothermal atomic absorption spectrometer fitted with a stabilised-temperature-platform furnace and Zeeman background correction. ${ }^{19,22}$ For 734 (74\%) participants, urinary arsenic was measured after arsine was generated under conditions that allow measurement of the sum of inorganic arsenic and its methylated metabolites (ie, monomethylarsonic acid and dimethylarsenic acid). ${ }^{23}$ In an external quality-control programme completed by Trace Element control scheme (organised by Robens Institute, University of Surrey, UK), the accuracy of the cadmium measurements did not differ significantly over time. ${ }^{22}$ For 260 participants who did not have data for 24-h urinary arsenic excretion, we calculated geometric mean excretion within the ten districts (ie, model A), or used a multiple regression equation, which included as predictor variables sex, the linear and squared terms of age, smoking, and nine design variables coding for the ten districts (ie, number of design variables=number of groups to be modelled-1; model B).

From 1985-89, soil samples were taken from 307 gardens owned by the CadmiBel participants by researchers at the Section of Environmental Biology, Department of Biology and Geology, University of Hasselt, Belgium..$^{5}$ Ten samples were obtained from the top layer of soil in every garden, at depths ranging from $0 \mathrm{~cm}$ to $25 \mathrm{~cm} .{ }^{4,5}$ Samples were dried for $24 \mathrm{~h}$ at $60^{\circ} \mathrm{C}$, passed through a sieve with holes of $2-\mathrm{mm}$ diameter, blended, digested in aqua regia, and analysed for cadmium by use of atomic absorption spectrometry. Participants' houses and zinc smelters were located by use of the global positioning system, GPS Pathfinder Pro XL (Trimble Navigation Europe, Hampshire, UK). Degrees longitude and latitude (projection of the earth's curved surface onto a flat map by use of ellipsoid WGS84) were converted into kilometres by use of the Lambert projection system of Belgian maps. We used SAS/GRAPH mapping software and the database of Teleatlas (Gent, Belgium). For privacy, we calculated spatial summary statistics for small geographic sectors (figure 1), consisting of one or two statistical units as defined by the Belgium national institute of statistics.

By use of the Belgium national population registry, we ascertained vital status of all participants until June 30, 2004. We obtained data for incidence of all non-fatal health outcomes by follow-up visits to participants' homes or at a local examination centre ${ }^{5,7}$ with repeated administration of the same standardised questionnaire as that used at baseline. Diseases reported on death

\begin{tabular}{|c|c|c|c|}
\hline & Low exposure $(n=473)$ & High exposure (n=521) & $\mathrm{p}$ \\
\hline \multicolumn{4}{|l|}{ Sex } \\
\hline Women & $257(54 \%)$ & $266(51 \%)$ & \multirow[t]{2}{*}{$0 \cdot 30^{*}$} \\
\hline Men & $216(46 \%)$ & $255(49 \%)$ & \\
\hline \multicolumn{4}{|l|}{ Age (years) } \\
\hline Median (range) & $45 \cdot 6(19 \cdot 8-91 \cdot 0)$ & $46.8(19.9-87.5)$ & $0.60+$ \\
\hline \multicolumn{4}{|l|}{ Smokers } \\
\hline Never & $197(42 \%)$ & $190(37 \%)$ & \multirow[t]{3}{*}{$0.36^{*}$} \\
\hline Past & $98(21 \%)$ & $120(23 \%)$ & \\
\hline Current & $178(38 \%)$ & $211(41 \%)$ & \\
\hline \multicolumn{4}{|l|}{ Socioeconomic status } \\
\hline Low (partly skilled or unskilled occupation) & $349(74 \%)$ & $451(87 \%)$ & \multirow[t]{3}{*}{$<0.0001^{*}$} \\
\hline $\begin{array}{l}\text { Medium (manual and non-manual skilled } \\
\text { occupation) }\end{array}$ & $117(25 \%)$ & $68(13 \%)$ & \\
\hline High (professional or intermediate occupation & 1) $7(2 \%)$ & $2(<1 \%)$ & \\
\hline \multicolumn{4}{|l|}{ Occupational exposure } \\
\hline Proportion (\%) & $3(1 \%)$ & $39(8 \%)$ & $<0.0001^{*}$ \\
\hline \multicolumn{4}{|l|}{ Serum creatinine $(\mu \mathrm{mol} / \mathrm{L})$} \\
\hline Mean (SD) & $97.8(24.1)$ & $101 \cdot 2(18 \cdot 5)$ & $0.017 \ddagger$ \\
\hline \multicolumn{4}{|l|}{ Urinary excretion of creatinine (mmol/day) } \\
\hline Mean (SD) & $12 \cdot 1(3 \cdot 9)$ & $12 \cdot 3(4 \cdot 4)$ & $0.59 \neq$ \\
\hline \multicolumn{4}{|l|}{ Distance to nearest smelter $(\mathrm{km})$} \\
\hline Geometric mean (IQR) & $10 \cdot 7(9 \cdot 7-12 \cdot 6)$ & $1.12(1.06-1.18)$ & $<0.0001 \ddagger$ \\
\hline \multicolumn{4}{|l|}{ Cadmium concentration in soil $(\mathrm{mg} / \mathrm{kg})$} \\
\hline Geometric mean (IQR) & $0.81(0.79-0.88)$ & $7.97(7.75-8.21)$ & $<0.0001 \ddagger$ \\
\hline \multicolumn{4}{|l|}{ Blood cadmium (nmol/L) } \\
\hline Geometric mean (IQR) & $10 \cdot 5(5 \cdot 4-11 \cdot 8)$ & $11 \cdot 9(11 \cdot 2-12 \cdot 8)$ & $0.0061 \ddagger$ \\
\hline \multicolumn{4}{|l|}{ Cadmium excretion (nmol/day) } \\
\hline Geometric mean (IQR) & $7 \cdot 7(7 \cdot 3-8 \cdot 2)$ & $12 \cdot 3(11 \cdot 5-13 \cdot 2)$ & $<0.0001 \ddagger$ \\
\hline \multicolumn{4}{|l|}{ Urinary excretion of arsenic $(\mathrm{nmol} / \mathrm{day}) \Omega$} \\
\hline Geometric mean (IQR) & $144 \cdot 5(80 \cdot 0-253 \cdot 6)$ & $323 \cdot 6(186 \cdot 8-600 \cdot 6)$ & $<0.0001 \ddagger$ \\
\hline Model A $\boldsymbol{T}$ & $146 \cdot 3(106 \cdot 8-226 \cdot 9)$ & $321 \cdot 3(170 \cdot 5-561 \cdot 7)$ & $<0.0001 \ddagger$ \\
\hline Model B\| & $146.8(93.4-226.9)$ & $340 \cdot 9(240 \cdot 3-546 \cdot 8)$ & $<0.0001 \neq$ \\
\hline $\begin{array}{l}\text { Data are number (\%), unless otherwise stated. *Fish } \\
\text { for } 397(84 \%) \text { in reference group and } 337(65 \%) \text { in } \\
\text { excretion of arsenic within every district for } 260 \mathrm{pec} \\
\text { from multiple regression equation that included the } \\
\text { nine design variables coding for the ten districts for }\end{array}$ & $\begin{array}{l}\text { her's exact test. † Mann-Whit } \\
\text { high-exposure group. } 9 \text { IData } \\
\text { ople with missing data for } 24 \\
\text { e predictor variables sex, age } \\
260 \text { people with missing da }\end{array}$ & $\begin{array}{l}\text { y test. fLarge-sample z test. } \$ \mathrm{~L} \\
\text { alculated from geometric mea } \\
\text { urinary arsenic excretion. } \| \mathrm{D}_{\mathrm{c}} \\
\text { inear and squared terms of age } \\
\text { for } 24 \text {-h h urinary arsenic excret }\end{array}$ & $\begin{array}{l}\text { ta available } \\
\text { נrinary } \\
\text { calculated } \\
\text { moking, and }\end{array}$ \\
\hline
\end{tabular}

certificates or questionnaires were checked systematically Aqua regia against records held by general practitioners, hospitals, A highly corrosive liquid used to or both by HC and JAS. If discrepancies were uncovered, dissolve metals, formed by a the diagnosis of the treating physician was accepted in fresh mixture of concentrated most cases. We coded diseases according to the hydrochloric acid, usually in a International Classification of Diseases (ICD), revision 8. ratio of one to three.

\begin{tabular}{|c|c|c|c|c|}
\hline & \multicolumn{2}{|c|}{ Low exposure $(n=473)$} & \multicolumn{2}{|c|}{ High exposure $(n=521)$} \\
\hline & Women $(n=257)$ & $\operatorname{Men}(n=216)$ & Women $(n=266)$ & Men $(n=255)^{*}$ \\
\hline Lung (ICD 162.0-163.9, 196.1) & 1 & 2 & 6 & 10 \\
\hline Colon (ICD 153.0-154.1) & 3 & .. & 2 & 4 \\
\hline Gastric (ICD 151.9) & 1 & 2 & .. & 2 \\
\hline $\begin{array}{l}\text { Gall bladder and pancreas } \\
(\text { ICD } 156 \cdot 0,156 \cdot 2,157 \cdot 0,157 \cdot 8)\end{array}$ & .. & 1 & 2 & 1 \\
\hline Urinary (ICD 188.0-189.0) & .. & .. & .. & 2 \\
\hline Prostate (ICD 185.0) & & 4 & & 2 \\
\hline Uterus and ovaries (ICD $182 \cdot 0,183.0)$ & 5 & .. & 1 & .. \\
\hline Breast (ICD 174.0) & & .. & 4 & .. \\
\hline Other (ICD 172.0, 200.0-209.9) & 4 & 4 & 3 & 4 \\
\hline
\end{tabular}

Table 2: Number of participants who developed cancer, by study area and sex 


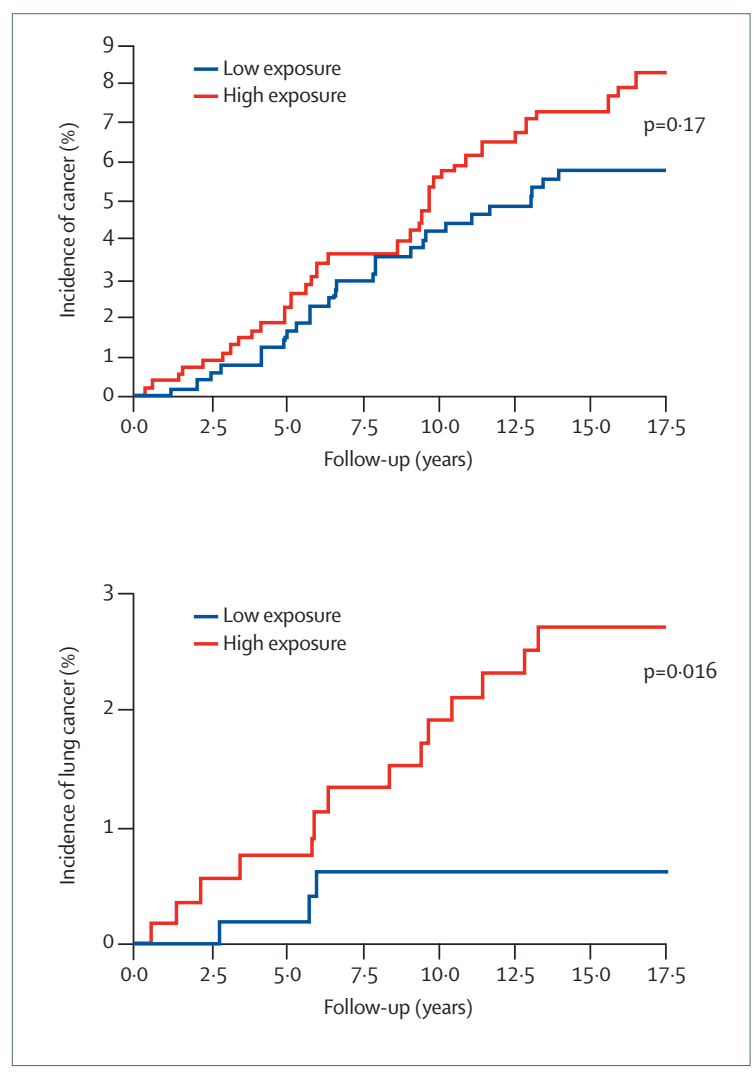

Figure 2: Incidence of all cancer and lung cancer in low-exposure and highexposure areas

We preplanned a case-control comparison as an internal validation of results: we used SAS RANBIN to match randomly 42 occupationally exposed men with 84 men of similar age (ie, within 5 years), smoking habits, and residence.

\section{Statistical analyses}

For database management and statistical analyses, we used SAS software version 8.2. We log-transformed nonnormally distributed data and reported these data as geometric mean and IQR. We compared means using the standardised normal $z$ test, medians using the MannWhitney test, and proportions using Fisher's exact test. We contrasted survival curves by Kaplan-Meier survival function estimates and the log-rank test. We used StatsDirect, version 2.4 to calculate the populationattributable risk with $95 \%$ CI. ${ }^{24}$ We investigated associations between variables by use of simple and multiple linear regression. We applied Cox regression to model the relation between failure time (ie, occurrence of fatal or non-fatal cancer) and the external (ie, soil) or internal (ie, urinary) exposure to cadmium, adjusting for other explanatory variables including sex, age, and smoking status. Additional explanatory variables in sensitivity analyses were number of pack years, duration that past smokers had ceased smoking, concentration of serum creatinine at baseline, and 24-h urinary arsenic excretion. In stepwise regression, we set $p$ values for variables to enter and stay in the model at $0 \cdot 10$. All p-values were for 2-sided tests. We based our samplesize calculation on the log-rank test: we assumed that the incidence of lung cancer in the low-exposure area would be much the same as that for the whole Flemish region. 25 cases of lung cancer and 360 participants from the low-exposure area and the high-exposure area were needed to show a three-times increased risk of lung cancer, with a 2 -sided $\alpha$ level of $5 \%$ and $80 \%$ power.

\section{Role of the funding source}

The funding source had no role in the study design; in the collection, analysis, and interpretation of the data; or in the writing of the report. The corresponding author had full access to all data and had final responsibility for the decision to submit for publication.

\section{Results}

At baseline, the characteristics of the 521 residents of the districts near the smelters (ie, in high-exposure areas) did not differ from those living in the low-exposure area with the exception of internal and external exposure to cadmium, internal exposure to arsenic and socioeconomic status (table 1). The median number of follow-up visits for ascertainment of non-fatal health outcomes

\begin{tabular}{|c|c|c|c|c|}
\hline & \multicolumn{2}{|l|}{ Total cohort $(n=994)$} & \multicolumn{2}{|c|}{ Environmental exposure $(n=952)$} \\
\hline & Hazard ratio $(95 \% \mathrm{Cl}) \dagger$ & $\mathrm{p}$ & Hazard ratio $(95 \% \mathrm{Cl}) \dagger$ & $\mathrm{p}$ \\
\hline \multicolumn{5}{|l|}{ All cancer‡ } \\
\hline Doubling of 24-h urinary cadmium excretion & $1.31(1.03-1.65)$ & 0.026 & $1 \cdot 29(1.00-1 \cdot 66)$ & 0.050 \\
\hline Doubling of cadmium concentration in soil & $1.10(0.95-1.27)$ & 0.189 & $1.08(0.93-1.26)$ & 0.298 \\
\hline High-exposure vs low-exposure area & $1 \cdot 31(0 \cdot 81-2 \cdot 12)$ & 0.276 & $1.28(0.77-2.13)$ & $0 \cdot 333$ \\
\hline \multicolumn{5}{|l|}{ Lung cancer\$ } \\
\hline Doubling of 24-h urinary cadmium excretion & $1.70(1.13-2.57)$ & 0.011 & $1.73(1.09-2 \cdot 72)$ & 0.019 \\
\hline Doubling of cadmium concentration in soil & $1 \cdot 57(1 \cdot 11-2 \cdot 24)$ & 0.012 & $1.49(1.04-2 \cdot 14)$ & 0.032 \\
\hline High exposure vs low-exposure & $4 \cdot 17(1 \cdot 21-14 \cdot 4)$ & 0.024 & $3.58(1.00-12 \cdot 7)$ & 0.049 \\
\hline
\end{tabular}




\begin{tabular}{|c|c|c|c|c|}
\hline & \multicolumn{2}{|l|}{ Total cohort $(n=994)$} & \multicolumn{2}{|c|}{ Environmental exposure $(n=952)^{*}$} \\
\hline & Hazard ratio $(95 \% \mathrm{Cl}) \dagger$ & $\mathrm{p}$ & Hazard ratio $(95 \% \mathrm{Cl}) \dagger$ & $\mathrm{p}$ \\
\hline \multicolumn{5}{|l|}{ All cancer‡ } \\
\hline Cadmium excretion, unadjusted for arsenic & $1.31(1.03-1.65)$ & 0.026 & $1 \cdot 29(1.00-1 \cdot 66)$ & 0.050 \\
\hline \multicolumn{5}{|l|}{ Cadmium excretion, adjusted for arsenic } \\
\hline Model AS & $1.28(1.01-1.63)$ & 0.041 & $1.26(0.97-1.63)$ & 0.085 \\
\hline Model B $\mathbf{T}$ & $1.29(1.01-1.65)$ & 0.043 & $1.26(0.97-1.64)$ & 0.084 \\
\hline \multicolumn{5}{|l|}{ Arsenic excretion, unadjusted for cadmium } \\
\hline Model AS & $1.10(0.93-1.35)$ & $0 \cdot 245$ & $1.13(0.93-1.37)$ & 0.226 \\
\hline Model B $\mathbf{T}$ & $1.10(0.91-1.34)$ & $0 \cdot 312$ & $1.11(0.91-1.35)$ & 0.310 \\
\hline \multicolumn{5}{|l|}{ Arsenic excretion, adjusted for cadmium } \\
\hline Model AS & $1.07(0.88-1 \cdot 30)$ & 0.495 & $1.08(0.89-1.33)$ & 0.415 \\
\hline Model B $\mathbf{T}$ & $1.04(0.85-1.27)$ & 0.692 & $1.05(0.86-1.30)$ & 0.611 \\
\hline \multicolumn{5}{|l|}{ Lung cancer|| } \\
\hline Cadmium excretion, unadjusted for arsenic & $1.70(1.13-2.57)$ & $0 \cdot 011$ & $1.73(1.09-2 \cdot 72)$ & 0.019 \\
\hline \multicolumn{5}{|l|}{ Cadmium excretion, adjusted for arsenic } \\
\hline Model A $\$ & $1.60(1.04-2 \cdot 45)$ & 0.031 & $1.61(1.00-2 \cdot 59)$ & 0.048 \\
\hline Model B $\mathbf{T}$ & $1.57(1.01-1.35)$ & 0.045 & $1.57(0.96-2.56)$ & 0.073 \\
\hline \multicolumn{5}{|l|}{ Arsenic excretion, unadjusted for cadmium } \\
\hline Model AS & $1.42(0.95-2 \cdot 12)$ & 0.088 & $1 \cdot 49(1 \cdot 04-2 \cdot 14)$ & 0.032 \\
\hline Model B $\mathbf{T}$ & $1.51(0.99-2.31)$ & 0.056 & $1.59(1.00-12 \cdot 7)$ & 0.043 \\
\hline \multicolumn{5}{|l|}{ Arsenic excretion, adjusted for cadmium } \\
\hline Model AS & $1.29(0.84-2.00)$ & $0 \cdot 247$ & $1 \cdot 32(0 \cdot 83-2 \cdot 11)$ & 0.234 \\
\hline Model B $\boldsymbol{\Psi}$ & $1.35(0.85-2.15)$ & 0.206 & $1.57(0.89-2.37)$ & 0.134 \\
\hline
\end{tabular}

was three (range 2-4). The proportion of smokers in districts with low exposure and high exposure were much the same (table 1). For current smokers, median daily tobacco consumption was 17 cigarettes (IQR 11-24) in 224 men and 15 cigarettes (10-20) in 165 women. For past smokers, median daily tobacco consumption was 16 cigarettes (10-25) in 145 men and 15 cigarettes (7-25) in 73 women. Median number of pack-years was $17.9(10.2-29.3)$ in men and 13.6 $(5 \cdot 8-22 \cdot 2)$ in women. During their lifetime, $42(9 \%)$ of 471 men and 0 of 523 women had been exposed to cadmium at work.

24-h urinary cadmium excretion increased with age by $2 \cdot 59$ (SE 0.29, p<0.0001) nmol per 10 years. Geometric mean cadmium excretion was higher at baseline in men than in women $(11.3 \mathrm{nmol} /$ day [IQR 6.5-19.4] vs $8.7 \mathrm{nmol} /$ day [5.7-13.6], $<<0 \cdot 0001)$, in ever smokers than in never smokers $(10 \cdot 8 \mathrm{nmol} /$ day $[6 \cdot 5-17 \cdot 3]$ vs $8 \cdot 6 \mathrm{nmol} /$ day [5.6-14.3], $<<0 \cdot 0001)$, and in cadmiumexposed workers than in men not occupationally exposed (26.9 nmol/day [19.7-39.7] vs $10 \cdot 4 \mathrm{nmol} /$ day $[6 \cdot 6-15 \cdot 1], p=0 \cdot 0001)$. In the case-control comparison of 42 occupationally exposed men and 84 men of similar age (ie, within 5 years), smoking habits, and residence, the occupationally exposed workers had significantly raised cadmium excretion $(26 \cdot 9 \mathrm{nmol} /$ day [19.7-39.7] vs $18 \cdot 1 \mathrm{nmol} /$ day [15·3-21·2], $\mathrm{p}=0 \cdot 006)$.

During follow-up from Sept 1, 1985, until June 30, 2004, 16681 person-years accrued. Median follow-up was much the same in areas with low exposure and high exposure, and totalled $17 \cdot 2$ years (range $0 \cdot 6-18 \cdot 8$ ). During follow-up, 50 fatal cancers and 20 non-fatal cancers occurred, of which 18 and one, respectively, were lung cancers (table 2). Figure 1 shows the geographical association between risk of lung cancer and 24-h urinary cadmium excretion. Incidence of lung cancer was significantly higher in the high-exposure area than in the low-exposure area (figure 2), with incidence of 1.80 per 1000 person-years and 0.38 per 1000 personyears, respectively $(\mathrm{p}=0 \cdot 016)$. Population-attributable risk of lung cancer was $67 \%$ (95\% CI 33-101) in the high-exposure area compared with that of 73\% (38-108) for smoking. Total incidence of cancer was 4.99 per 1000 person-years in the high-exposure area and $3 \cdot 55$ cases per 1000 person-years in the low-exposure area $(\mathrm{p}=0 \cdot 17)$.

Risk of cancer was not associated with sex $(\mathrm{p}=0 \cdot 13)$ or socioeconomic status $(\mathrm{p}=0 \cdot 51)$. However, every 10 -year increase in age at enrolment was associated with a hazard ratio of $1 \cdot 64$ (95\% CI 1.24-2.18, p=0.0006) for lung cancer and $1.63(1.41-1.89, \mathrm{p}<0.0001)$ for all cancer. The hazard ratio for smokers was 4.39 $(1 \cdot 58-12 \cdot 2, \mathrm{p}=0 \cdot 0045)$ and for non-smokers was $1 \cdot 39$ $(0 \cdot 87-2 \cdot 23, p=0 \cdot 17)$. With additional adjustment for 24-h urinary cadmium excretion, the hazard ratio for smoking versus non-smoking was $3.69(1 \cdot 31-10 \cdot 30$, $\mathrm{p}=0 \cdot 013)$ for lung cancer and was $1 \cdot 26(0 \cdot 78-2 \cdot 03$, $\mathrm{p}=0 \cdot 33$ ) for all cancer. Analyses of the total cohort adjusted for sex, age, and smoking at baseline showed a significant association between 24-h urinary cadmium 
excretion and all cancer or lung cancer (table 3); we also recorded a significant association between cadmium concentration in the soil or residence in the highexposure area and lung cancer (table 3). Our results remained consistent when we replaced the adjustment for ever-smoking with that of current smoking (hazard ratio $1.59[1.08-2 \cdot 34], \mathrm{p}=0.018)$ or with number of pack-years $(1.76[1.17-2.63], \quad \mathrm{p}=0.006)$, when we accounted for duration that past smokers had stopped smoking $(<10$ years $v s \geqslant 10$ years; 1.68 [1.12-2.52], $\mathrm{p}=0 \cdot 013$ ), when we adjusted for concentration of serum creatinine $(1.73[1 \cdot 16-2 \cdot 59], p=0.007)$, or when we used the ratio of cadmium to creatinine concentration in urine as a biomarker of cadmium exposure (1.61 $[1 \cdot 05-2 \cdot 47], \mathrm{p}=0 \cdot 028)$.

Of 42 workers exposed to cadmium, four developed lung cancer during follow-up and four developed other cancer. On adjustment for age and ever smoking, cadmium-exposed workers had a hazard ratio of $3 \cdot 23$ times $(1 \cdot 00-10 \cdot 8, \mathrm{p}=0 \cdot 05)$ for lung cancer than did environmentally exposed men. Sensitivity analyses, in which we adjusted for occupational exposure to cadmium or from which we excluded the 42 occupationally exposed men, confirmed our findings (table 3).

Data for 24-h urinary arsenic excretion were available for 397 (84\%) people in the low-exposure area and 337 $(65 \%)$ in the high-exposure area. 43 of these 734 individuals developed any cancer $161 \%$ of those occurring in the total cohort), and 11 developed lung cancer $(58 \%$ of those arising in total cohort). For individuals with data for urinary arsenic, neither cadmium excretion nor arsenic excretion were significant predictors of any cancer or of lung cancer. For any cancer, the hazard ratio associated with a doubling of biomarker of exposure on adjustment for sex, age, and smoking was $1.04(0.71-1.53, \mathrm{p}=0.82)$ for cadmium and was $1 \cdot 09(0 \cdot 87-1 \cdot 31, \mathrm{p}=0 \cdot 51)$ for arsenic. For lung cancer, the corresponding hazard ratios were 1.38 $(0 \cdot 63-3 \cdot 01, p=0 \cdot 41)$ for cadmium and $1 \cdot 42(0 \cdot 90-2 \cdot 23$, $\mathrm{p}=0 \cdot 13$ ) for arsenic, respectively. In further analyses that calculated urinary arsenic excretion for 260 people by use of two different models, only unadjusted analyses of the environmentally exposed cohort showed 24-h urinary arsenic excretion to be a significant predictor of lungcancer incidence, but not all cancer (table 4). Urinary arsenic excretion lost its prognostic role on adjustment for cadmium. By contrast, urinary cadmium excretion remained a significant predictor of any cancer and of lung cancer after adjustment for arsenic in the whole cohort, and for lung cancer (model A) in those who were environmentally exposed (table 4).

\section{Discussion}

We have shown an association between risk of cancer and cadmium exposure as shown by $24-\mathrm{h}$ urinary excretion-a finding that remained consistent after: adjustment for sex, age, and smoking; exclusion of
42 cadmium-exposed workers; and accounting for exposure to inorganic arsenic.

Cadmium is a ubiquitous environmental pollutant in industrialised countries. Residence in the area with high environmental exposure to cadmium was associated with a hazard ratio for lung cancer of $3 \cdot 58$. Our current findings might remove some uncertainty about the association between cadmium exposure and cancer risk, doubt that comes from a large number of human studies on the association between cytogenetic endpoints and exposure to cadmium. ${ }^{9,25}$ Our findings are also consistent with circumstantial evidence from a previous study of mortality statistics in north-east Belgium: ${ }^{26}$ Buchet and Lison ${ }^{26}$ noted that standardised rate ratios for death from lung cancer were unrelated to moderate environmental exposure to arsenic via air (ie, $0.3 \mu \mathrm{g} / \mathrm{m}^{3}$ ) or drinking water (ie, $20-50 \mu \mathrm{g} / \mathrm{L}$ ), but also recorded a higher proportion of death from lung cancer in areas with zinc smelters compared with areas without such plants. In 1992-94, the age-standardised incidence of lung cancer per 100000 Flemish residents was 64.2 (113.6 in men and 16.0 in women). ${ }^{27}$ Our study was in progress for a median of $17 \cdot 2$ years, and assuming that these incidence rates would apply equally to the whole region and total follow-up, ten individuals would be expected to develop lung cancer, equally distributed over the two areas with low exposure and high exposure. Moreover, the incidence of lung cancer we recorded in the high-exposure area exceeded that expectation by more than three times.

Findings from studies in workers cannot be extrapolated to the general population. Employers select healthy people for physically demanding labour, which explains the so-called healthy-worker effect. ${ }^{\text {' }}$ Furthermore, compared with the general population, workers in the non-ferrous industry are exposed to higher levels of cadmium, mainly through inhalation of contaminated dust or fumes frequently in the presence of other toxic substances. Consistent with findings from early studies reviewed by Verougstraete and colleagues, ${ }^{9}$ cadmiumexposed workers in our study had greater risk of lung cancer than did environmentally exposed men. For these reasons, we recalculated hazard ratios after exclusion of 42 workers with a history of exposure to cadmium at work. Findings in this environmentally exposed cohort were confirmatory.

Inorganic arsenic is a strong carcinogen. Particularly in the past when environmental regulations were less stringent, emissions from zinc and copper smelters were important sources of inorganic arsenic. Bessö and colleagues $^{28}$ found that with adjustments for smoking and occupational exposure, the relative risk of lung cancer for people who lived within $20 \mathrm{~km}$ of a large copper smelter was $1.38(95 \%$ CI $0 \cdot 89-2 \cdot 14)$ in men and $0.88(0.48-1.62)$ in women. These researchers suggested that the increased hazard ratio in men, although not significant, might be attributable to arsenic 
exposure. In the high-exposure area of our study, the arsenic concentration in the soil of kitchen gardens (ie, a garden in which vegetables are grown for home use) was raised (ie, $>20$ parts per million) in Overpelt and Lommel, and especially near the zinc smelter in Lommel that was dismantled in $1974 .^{23}$ The general population is exposed to inorganic arsenic through inhalation of polluted dust particles, ingestion of contaminated food or water pumped from geological layers containing arsenic, and possibly through smoking. ${ }^{26}$ 24-h urinary excretion of arsenic is a biomarker of recent exposure (ie, about 3 days), and in unexposed people is usually less than $200 \mathrm{nmol}$ per day. In 1985-89, geometric mean 24-h urinary arsenic excretion was $144 \mathrm{nmol}$ (IQR 80-253) in Hechtel and Eksel, $158 \mathrm{nmol} \mathrm{(106-227)} \mathrm{in}$ Balen, $373 \mathrm{nmol}$ (253-547) in Overpelt and Neerpelt, and $570 \mathrm{nmol}$ (394-827) in Lommel (figure 1). ${ }^{23}$ Confounding by arsenic is unlikely to explain our recorded association between risk of lung cancer and exposure to cadmium. Moreover, 24-h urinary arsenic excretion was a significant predictor of lung cancer only in unadjusted analyses and lost its prognostic role after adjustment for cadmium. By contrast, on adjustment for arsenic, 24-h urinary cadmium excretion remained a significant predictor of all cancer and lung cancer in the whole cohort and of lung cancer (model A) in those who were environmentally exposed.

Three lines of evidence explain why the International Agency for the Research on Cancer ${ }^{8}$ classified cadmium as a human carcinogen. First, as reviewed by Verougstaete and colleagues, ${ }^{9}$ several, ${ }^{10,11,13,14}$ but not all ${ }^{12,15}$ studies in workers showed a positive association between risk of lung cancer and occupational exposure to cadmium; discrepancies between these studies should not be ascribed to the better design of the more recent studies. ${ }^{9}$ Verougstraete and colleagues ${ }^{9}$ and Sorahan and Lancashire $^{13}$ suggested that such inconsistencies might be attributed to the high relative risk of cancer in the presence of coexposure to arsenic, nickel, or toxic fumes, and Sorahan and Esmen ${ }^{15}$ suggested that the increasingly stringent regulations with regard to levels of exposure permissible at work might be a factor. Second, data from rats showed that the pulmonary system is a target site for carcinogenesis after cadmium inhalation. ${ }^{29}$ However, exposure to toxic metals in animal studies have usually been much higher than those reported for human beings who had been environmentally exposed to toxic metals. ${ }^{30}$ Third, several studies done in vitro have shown plausible pathways such as increased oxidative stress ${ }^{29}$ modified activity of transcription factors, ${ }^{31}$ and inhibition of DNA repair. ${ }^{32,33}$ However, the role of these pathways in the response to toxic-metal exposure has not been defined in human beings.

Our study should be interpreted within the context of its possible limitations. Observational studies, even if prospective and based on predefined hypotheses, do not prove causality. The number of people who developed cancer was fairly small. In analyses of the role of arsenic as a potential confounder of the relation between cancer risk and cadmium exposure, we had to calculate urinary arsenic excretion for $26 \%$ of the study population, implying a greater level of uncertainty than for the recorded cadmium data-a factor that will affect the overall interpretation of current evidence. Furthermore, we cannot exclude with certainty that cancer risk in the vicinity of smelters might be related to pollutants other than cadmium that are emitted during refining or smelting of zinc. However, on the basis of our current findings and an ecological mortality study ${ }^{26}$ the possibility that arsenic might be involved is unlikely.

However, we assessed fatal and non-fatal outcomes. As exemplified by the closely similar incidence of all cancer in areas with low exposure and high exposure, all participants were followed up equally, irrespective of area of residence. We recruited participants from Sept 1 , 1985 , to Dec 17, 1989. That after about 6 years of followup no new cases of lung cancer occurred in the lowexposure area probably reflects the history of the airborne exposure to cadmium. In the study region, zinc smelters had emitted cadmium into the atmosphere since 1888., ${ }^{54}$ Cadmium concentration in the soil is a historical record of the pollution: in the early 1970s, zinc ovens were replaced by electrolytic refining such that airborne cadmium emissions dropped from $125000 \mathrm{~kg}$ in 1950 to $130 \mathrm{~kg}$ in $1989 .{ }^{34}$ In Lommel and Overpelt, the emission of cadmium fell from $12 \mathrm{mg} / \mathrm{m}^{2}$ a day in 1985 to less than $0 \cdot 01 \mathrm{mg} / \mathrm{m}^{2}$ a day in $1994 .{ }^{34}$ However, in the polluted area, cadmium emitted in the past continues to contaminate the soil and remains a source of contaminated particles. In 2002, the industry reported a total toxic metal load of about $9902 \mathrm{~kg}$ per year in the high-exposure area, compared with loads of $12-2100 \mathrm{~kg}$ per year in settlements of the same company in western Europe and North America. ${ }^{35}$ In 473 participants of our study, 24-h urinary cadmium excretion increased by $3 \%$ $(\mathrm{p}=0 \cdot 0007)$ for every 2 -fold increase in cadmium loading rate in house dust (median $0.16 \mathrm{ng} / \mathrm{cm}^{2}$ [5th to 95th percentile $0 \cdot 04-1 \cdot 27 \mathrm{ng} / \mathrm{cm}^{2}$ ] per 92 days; Vangronsveld $\mathrm{J}$, unpublished data). These findings highlight that in areas with historically contaminated soils, house dust is a potential persistent source of exposure, with the lungs being both the route of entrance and a potential target.

In conclusion, consistent with indirect evidence currently available, we have shown a significant association between risk of lung cancer and environmental exposure to cadmium. To our knowledge, this is the first time such an association has been reported in an environmentally exposed population. These findings suggest that continuing or past pollution from nonferrous smelters continues to present a serious health hazard, necessitating targeted preventive measures. A signed agreement between the Flemish government and industry will force the company to sanitise soil in the immediate vicinity of the former zinc smelters. 
Remarkably, their agreement leaves the Flemish government as the only party responsible for the consequences of past pollution in the wider surroundings of industrial settlements.

\section{Contributors}

J A Staessen designed and coordinated the prospective population study and organised the database. H Celis took part in ICD coding. T Nawrot and L Thijs did statistical analyses and, together with J A Staessen, wrote the first draft. E Van Hecke helped with geographical analyses. $\mathrm{H}$ Roels supervised measurements of blood and urinary cadmium. J Hogervorst, M Plusquin, and J Vangronsveld determined cadmium in external media. All authors took part in the interpretation of the results and prepared the final version.

\section{Conflict of interest}

$\mathrm{H}$ Roels was a member of the scientific review panel (health) for the Voluntary Risk Assessment Report on Lead and Lead Compounds drafted by the International Lead Zinc Research Organization (ILZRO, Research Triangle Park, NC, USA), the European Bio-Research Consultants (EBRC Consulting GmbH, Hannover, Germany), and the Lead Development Association International (LDAint, London, UK) in the framework of the EU Chemicals Bureau Existing Substances Programme. All other authors declare no conflicts of interest.

\section{Acknowledgments}

ILZRO supported the follow-up of study participants from Jan 25, 1990 to Feb 24, 1994. The municipality of Hechtel-Eksel provided logistical support. We thank Rina Bollen, Johan Boon, Sandra Covens, Lieve Gijsbers, Marie-Jeanne Jehoul, Hanne Truyens, Hilde Vandenhoeck, Sylvia Van Hulle, and Renilde Wolfs for assistance.

\section{References}

1 Järup L, Berglund M, Elinder CG, et al. Health effects of cadmium exposure- a review of the literature and a risk estimate. Scand J Work Environ Health 1998; 24 (suppl 1): 1-51.

2 International Programme on Chemical Safety (IPCS). Environmenal health criteria 134. Cadmium (ISBN 92-4-157134-9) 2005. http://www.inchem.org/documents/ehc/ehc/ehc134.htm (accessed 24 October 2005).

3 Sartor F, Rondia D, Claeys F, et al. Impact of environmental pollution by cadmium on the cadmium exposure and body burden Arch Environ Health 1992; 47: 347-53.

4 Buchet JP, Lauwerys R, Roels H, et al. Renal effects of cadmium body burden of the general population. Lancet 1990; 336: 699-702.

5 Staessen JA, Lauwerys RR, Ide G, et al. Renal function and historical environmental cadmium pollution from zinc smelters. Lancet 1994; 343: 1523-27.

6 Staessen J, Amery A, Bernard A, et al. Effects of exposure to cadmium on calcium metabolism: a population study. Br J Ind Med 1991; 45: 710-14.

7 Staessen JA, Roels HA, Emelianov D, et al. Environmental exposure to cadmium, forearm bone density, and risk of fractures: prospective population study. Lancet 1999; 353: 1140-44.

8 International Agency for Research on Cancer. Cadmium and cadmium compounds. Lyon: International Agency for Research on Cancer, 1993: 119-220.

9 Verougstraete V, Lison D, Hotz P. Cadmium, lung and prostate cancer: a systematic review of recent epidemiological data. $J$ Toxicol Environ Health 2003; 6: 227-55.

10 Kazantzis G, Blanks RG, Sullivan KR. Is cadmium a human carcinogen? In: Nordberg GF, Herber RFM, Alessio L, eds. Cadmium in the human environment: toxicity and carcinogenicity. Lyon: International Agency for Research on Cancer, 1992: 435-46.

11 Järup L, Bellander T, Hogstedt C, Spång G. Mortality from cancer incidence in Swedish battery workers exposed to cadmium and nickel. Occup Environ Med 1998; 55: 755-59.

12 Sorahan T, Lister A, Gilthorpe MS, Harrington JM. Mortality of copper cadmium alloy workers with special reference to lung cancer and non-malignant diseases of the respiratory system, 1946-92. Occup Environ Med 1995; 52: 804-12.

13 Sorahan T, Lancashire RJ. Lung cancer mortality in a cohort of workers employed at a cadmium recovery plant in the United States: an analysis with detailed job histories. Occup Environ Med 1997; 54: 194-201.
14 Sorahan T, Waterhouse JA. Mortality of nickel-cadmium battery workers by the method of regression models in life tables. Br J Ind Med 1983; 40: 293-300.

15 Sorahan T, Esmen NA. Lung cancer mortality in UK nickelcadmium battery workers, 1947-2000. Occup Environ Med 2004; 61: 108-16.

16 Nakagawa H, Nishijo M, Morikawa Y, et al. Increased urinary beta2-microglobulin and mortality rate by cause of death in a cadmium-polluted area. Environ Health Prevent Med 1996; 1: $144-48$.

17 Nishijo M, Nakagawa H, Morikawa Y, et al. Mortality in a cadmium polluted area in Japan. Biometals 2004; 17: 535-38.

18 Nakagawa H, Kawano S, Okumura Y, et al. Mortality study of inhabitants in a cadmium-polluted area. Bull Environ Contam Toxicol 1987; 38: 553-60.

19 Lauwerys R, Amery A, Bernard A, et al. Health effects of environmental exposure to cadmium: objectives, design and organization of the Cadmibel study: a cross-sectional morbidity study carried out in Belgium from 1985 to 1989. Environ Health Perspect 1990; 87: 283-89.

20 Cohen R, Velho V. Update on respiratory disease from coal mine and silica dust. Clin Chest Med 2002; 23: 811-26.

21 Office of Population Censuses and Surveys. Classification of occupations and coding index. London: HM Stationery Office, 1980.

22 Claeys F, Ducoffre G, Sartor F, Roels H. Analytical quality control of cadmium and lead in blood and cadmium in urine: results of its implementation during a five-year epidemiological study. In: Nordberg GF, Herber RFM, Alessio L, eds. Cadmium in the human environment: toxicity and carcinogenicity. Lyon: International Agency for Research on Cancer, 1992: 83-92.

23 Buchet JP, Staessen J, Roels H, et al. Geographical and temporal differences in the urinary excretion of inorganic arsenic: a Belgian population study. Occup Environ Med 1996; 53: 320-27.

24 Rowe AK, Powell KE, Flanders D. Why population attributable risk fractions can sum to more than one. Am J Prev Med 2004; 26: $243-49$.

25 Verougstraete V, Lison D, Hotz P. A systematic review of cytogenetic studies conducted in human populations exposed to cadmium compounds. Mutat Res 2002; 511: 15-43.

26 Buchet JP, Lison D. Mortality by cancer in groups of the Belgian population with a moderately increased intake of arsenic. Int Arch Occup Environ Health 1998; 71: 125-30.

27 Drieskens S, Van Oyen H, Tafforeau J, et al. Overlijden en oorzaakspecifiek overlijden in de Vlaamse gemeenschap 1992-1994. Brussels: Centre of Operational Research in Public Health, Scientific Institute of Public Health, Administration of Health, Ministry of the Flemish Community, 1999: 160-71.

28 Bessö A, Nyberg F, Pershagen G. Air pollution and lung cancer mortality in the vicinity of a nonferrous metal smelter in Sweden. Int J Cancer 2003; 107: 448-52.

29 Waalkes MP. Cadmium carcinogenesis. Mutat Res 2003; 533: 107-20.

30 Staessen JA, Lauwerys RR, Bulpitt CJ, et al. Is a positive association between lead exposure and blood pressure supported by animal experiments? Curr Opin Nephrol Hypertens 1994; 3: 257-63.

31 Watkin RD, Nawrot T, Potts RJ, Hart BA. Mechanisms regulating the cadmium-mediated suppression of Sp1 transcription factor activity in alveolar epithelial cells. Toxicology 2003; 184: 157-78.

32 Jin YH, Clark AB, Slebos RJC, et al. Cadmium is a mutagen that acts by inhibiting mismatch repair. Nat Genet 2003; 34: 326-29.

33 Hartwig A, Asmuss M, Ehleben I, et al. Interference by toxic metal ions with DNA repair processes and cell cycle control: molecular mechanisms. Environ Health Perspect 2002; 110: 797-99.

34 Staessen J, Roels H, Vangronsveld J, et al. Preventiemaatregelen voor bodemverontreiniging met cadmium. Tijdschr voor Geneeskd 1995; 51: 1387-95.

35 Umicore. Environment and safety. Report 2002. http://www.umicore.com/coehs/index.htm (accessed Jan 2, 2004). 